\title{
DISCRIMINAÇÃO SALARIAL ENTRE NATIVOS E NÃO NATIVO NO ESTADO DE SÃO PAULO EM 2015
}

\section{SALARY DISCRIMINATION BETWEEN NATIVE AND NON-NATIVE IN THE STATE OF SAO PAULO IN 2015}

\author{
Fernanda Cristina Ferro Malacoski* \\ Carolina Freitas ${ }^{* *}$ \\ Cristiano Stamm ${ }^{* * *}$ \\ Jeffeson Andronio Ramundo Staduto ${ }^{* * * *}$
}

\begin{abstract}
RESUMO
O fluxo migratório a São Pauloé um dos mais importantes do Brasil. Os trabalhadores deslocam-se para outras cidades, regiões ou países permitindo a discriminação por parte dos nativos em relação aos migrantes. O presente estudo teve como objetivo analisar a discriminação salarial entre nativos e não nativos que estão no Estado de São Paulo de acordo com o setor agrícola, o industrial e o comércial para o ano de 2015. Para a análise foi utilizado o método de decomposição salarial OaxacaBlinder e para isso foi utilizado a base de microdados da Pesquisa Nacional de Amostra por Domicílios (PNAD) do ano de 2015. Na análise dos dados ficou evidente que existe discriminação entre esses dois grupos de trabalhadores (nativo e não nativo) e que a discriminação apresenta intensidade diferente dependendo do ramo de atividade que estes estão inseridos.
\end{abstract}

Palavras-Chave: Migrantes, Nativos, Discriminação Salarial, Oaxaca-Blinder.

\begin{abstract}
The migratory flow to State of São Paulo is one of the most important in Brazil. Workers move to other cities, regions or countries allowing discrimination on the part of the natives in relation to the migrants. This study aimed to analyze the wage discrimination between natives and non-natives who are in the State of São Paulo according to the sector agricultural, industrial and commercial sectors for the year 2015. For the analysis, the Oaxaca-Blinder wage decomposition method was used and the microdata base of the National Household Sample Survey (PNAD) for the year 2015. In the analysis of the data it was evident that there is discrimination between these two groups of workers (native and non-native) and that the discrimination presents different intensity depending on the branch of activity that these are inserted.
\end{abstract}

Key-Words: Migrants, Natives, Wage Discrimination, Oaxaca-Blinder.

"Mestre em Desenvolvimento Regional e Agronegócio pela Universidade Estadual do Oeste do Paraná

"* Mestre em Teria Econômica pela Universidade Estadual do Oeste do Paraná

*** Doutor em Planejamento Urbano e Regional pela Universidade Federal do Rio Grande do Sul

**** Doutor em Ciências (Economia Aplicada) pela Universidade Federal de Viçosa 


\section{INTRODUÇÃO}

Marcado pela industrialização na década de 1930, a região Sudeste (São Paulo, Rio de Janeiro, Minas Gerais e Espírito Santo) teve como fundamentação a concentração de capital humano. A tendência de migração de mão-de-obra do meio rural para o urbano permaneceu até o final da década de 1970, em que políticas de desenvolvimento regional surtiram efeitos positivos (DEDECCA; CUNHA, 2004). Na contemporaneidade, os fluxos migratórios se tornaram complexos, redefinido suas extremidades, conduzindo a migração de longa permanência (BAENINGER, 2011).

Referenciado como o "coração da economia nacional", o estado de São Paulo revela o seu longo histórico brasileiro de migrações, mostrando oscilações a concentração de capital humano entre as décadas de 1970 a 1990. No primeiro momento, o forte fluxo migratório apresentou uma força centrípeta, viabilizando a emigração rural; nos anos de 1980 a contenção do interesse populacional em residir na região metropolitana de São Paulo decresceu, devido aos efeitos de políticas de desenvolvimento; entretanto, nos anos de 1990, esses fluxos se deram, novamente, de forma centrípeta (BAENINGER, 2005).

Conforme Dedecca e Cunha (2004), os fluxos migratórios para a região paulista apresentam impactos essenciais no mercado de trabalho local. Destacase a importância de compreender as consequências desse processo ao mercado de trabalho e a discriminação salarial do capital humano migrante.

Segundo Lowell (1995) a discriminação salarial é delineada pela similaridade de qualificações de trabalhadores inseridos na mesma categoria de ocupação, mas com salários divergentes, em razão da disposição de diferenças que não agregam salarialmente entre o mesmo nível técnico.

Ao compreender a experiência do migrante no mercado de trabalho, se tem como questão a discriminação salarial, quando comparada ao nativo; ocasionando na insatisfação do capital humano por sua posição ocupada. (PIORE, 1979). Isto posto, a questão que norteou o presente artigo é: existe discriminação salarial entre nativos e não nativos nos setores econômicos do estado de São Paulo no ano de 2015?

Assim, o escopo do artigo é analisar a discriminação salarial entre nativos e não nativos por atividade econômica, a fim de identificar a discriminação salarial por setor referente entre os migrantes e paulistas, com o intuito de reconhecer um maior desenvolvimento do mercado de trabalho através de políticas públicas econômicas e sociais. Para análise da pesquisa, foi utilizada a metodologia de decomposição salarial de Oaxaca-Blinder e a base de microdados da Pesquisa Nacional por Amostra de Domicílios (PNAD), do ano de 2015. As variáveis escolhidas para análise foram anos de estudo, experiência, horas de trabalho, idade, setores (agrícola, comércio e industrial), nativos e não nativos do estado de São Paulo.

Este trabalho está subdivido em quatro itens, além desta introdução. No segundo tópico, é apresentado os aspectos teóricos sobre o mercado de trabalho, mão-de-obra, migração e imigração. Na terceira seção apresentada é descrita a metodologia Oaxaca-Blinder (1973) e base de dados utilizada na pesquisa. A quarta seção foi reservada para a análise da relação dos dados entre nativos e não nativos em questão assim como para frisar a discriminação salarial. Por fim, mas não menos importante, é apresentada as considerações finais realizadas a partir da pesquisa.

\section{REFERENCIAL TEÓRICO}

Os gastos que o indivíduo realiza em favor da sua educação, saúde e migração em busca de melhores oportunidades de empregos são exemplos de investimentos em capital humano. São esses investimentos, os responsáveis por grande parte das justificativas do aumento da renda do trabalhador (SCHULTZ, 1973).

Lima (1980), porém, apresenta algumas críticas quando a efetividade dos investimentos que o trabalhador realiza em educação formal. As provas empíricas de que a relação entre aumento em anos de estudo e o aumento de renda não é sempre verificada. Além do que, existem teorias que visualizam a educação formal como um processo de criar credenciais.

Mesmo diante dessa dicotomia, alguns trabalhadores possuem mais escolaridade, experiência e demais atributos que os tornam mais produtivos. Com atributos superiores aos demais trabalhadores, os salários recebidos são mais elevados. Nesse caso, a desigualdade do salário é um reflexo da diferença de produtividade existente na mão de obra disponível (BARROS; FRANCO; MENDONÇA, 2007). 
Arbache (2000) ao aplicar a Teoria do Preço Único ao mercado de trabalho postula que se dois trabalhadores apresentarem o mesmo nível de escolaridade formal, ocupação, idade e sexo eles devem ser remunerados igualmente. Porém, a despeito disso, nem sempre é possível ser observada essa igualdade de remuneração entre trabalhadores com as mesmas características. Isso porque, não são apenas as particularidades de cada trabalhador que estão associadas aos rendimentos. Além disso, aspectos demográficos como raça, sexo, etnia, região geográfica, cultura, características do empregador são alguns dos determinantes para a explicação do diferencial salarial.

Para além das diferenças de produtividade encontradas no mercado de trabalho, existem trabalhadores que são perfeitamente substituíveis. Nesse caso, diz-se que se um posto de trabalho for ocupado por outro trabalhador, o nível de produção seria o mesmo. Esse é o retrato da discriminação no mercado de trabalho, oriundo de diferenças atribuídas a determinados trabalhadores, mesmo quando eles apresentam a mesma característica (BARROS; FRANCO; MENDONÇA, 2007). Vale ressaltar que o exército industrial de reserva, atribuído aos estudos de Karl Marx, também influenciam nas determinações salariais, porém não discutidas neste artigo.

A discriminação acontece então, quando os trabalhadores recebem salários diferentes devido a preferências do empregador. Ou seja, trabalhadores com habilidades similares e mesma função, recebem remuneração melhor porque o empregador prefere determinadas características demográficas em relação a outras (ARBACHE, 2000).

Lima (1980) contribui com a discussão da desigualdade ao atribuir o diferencial salarial ao tipo de mercado de trabalho em que o trabalhador está inserido. Isso porque, no mercado de trabalho primário a renda do indivíduo aumenta com os anos de estudos, mas isso não é observado no mercado secundário. $\mathrm{O}$ mercado primário é definido como aquele em que os salários e a produtividade são altos, os empregos são estáveis e existe progresso tecnológico. E, no mercado de trabalho secundário, pode ser delimitado como aquele que apresenta salários e produtividades baixos, alta rotatividade de mão de obra, pouco treinamento e possibilidade de ascensão salarial.

Nesse sentido, trabalhadores inseridos em setores com alto nível tecnológico recebem maiores salários devido a complementaridade entre capital e trabalho, bem como altos custos associados a rotatividade da mão de obra (ARBACHE, 2000). Assim, percebe-se que as pessoas investem em educação na expectativa de ganhos futuros. Mas, mesmo que a o nível de investimento em educação sejam o mesmo, isso não representa necessariamente aumento nos rendimentos ou equidade de salários. Para Arbache (2000) a explicação pode estar relacionada tanto as características individuais do trabalhador, como resultado da discriminação, quanto estar relacionada ao tipo de mercado de trabalho, relacionado com a segmentação do mercado.

O que se observa é que a educação não é suficiente para explicar os acréscimos na renda do trabalhador, e este está sujeito a diversas fontes de discriminação - como preparação, características demográficas ou do mercado de trabalho. Assim, quando em busca de oportunidades o indivíduo é impelido a migrar, este pode sofrer uma nova fonte de discriminação oriunda da região geográfica de origem. Para Schultz (1973), a migração interna de trabalhadores é importante, por atender as exigências do crescimento econômico, suprindo as oscilações de possibilidades de emprego.

O processo de migração não afeta apenas o mercado de trabalho da região de destino, mas, sobretudo impacta nas dificuldades que esse trabalhador encontra para a sua inserção em um novo emprego. Dedecca e Cunha (2000) observaram que a Região Metropolitana de São Paulo possui elevada concentração de riqueza o que a torna atrativa para os trabalhadores. Apesar disso, tem perdido capacidade de reter a população migrante, como resultado, estes são alocados em segmentos mais precários e periféricos do mercado de trabalho, em ocupações que exigem menor qualificação e oferecem remuneração menor.

As motivações para a migração são expectativas de melhor condição de trabalho e de vida, sendo uma alternativa diante de problemas econômicos, sociais, políticos, raciais e religiosos. A vertente econômica é a principal explicação para a migração de trabalhadores que em países subdesenvolvidos enfrentam a escassez de trabalho e oportunidade local, enquanto que outros locais apresentam procura por mão de obra. Essa realidade faz com que trabalhadores se submetam a mudança de residência, inclusive dirigindo-se a outros países (SANTIN, 2008). 
A migração compõe um conjunto de elementos que influenciam a escolha de entrar no mercado de trabalho. Os trabalhadores migram com o objetivo de encontrar um cenário mais favorável do que onde estão inseridos, quando se trata, por exemplo: de rendimento; setor; carreira; e benefícios trabalhistas (GAMA; MACHADO, 2014). Os migrantes têm como objetivo migrar para localidades:

que ofereçam oportunidade de vida que não encontram onde vivem. Algumas cidades são atrativas pelo fato de serem conhecidas como espaços oficiais de trabalho, pela presença de uma economia diversificada, marcada fundamentalmente por indústrias, fábricas, serviços e chances de emprego e trabalho (HERÉDIA, 2010, p. 4).

Alguns municípios são caracterizados como "atração de pessoas que enxergam neles oportunidades de ascensão social, e como centros de expulsão, para aquelas que não conseguiram materializar essa expectativa ou que estão em busca de novas oportunidades" (ANDRADE; SANTOS; SERRA, 2001, p.178). Os trabalhadores deslocam-se para outras cidades, regiões ou países, onde enxergam possibilidades, permitindo a discriminação por parte dos nativos em relação aos migrantes devido às dificuldades de adequação psicológica, social e cultural. Dessa forma, "o trabalhador migrante ou imigrante pode sofrer discriminação por parte do povo da terra. A discriminação pode ter base política, econômica, sociológica, racial e sexual" (SANTIN, 2008, p.136).

Quando se trata dos fluxos migratórios internos de um país, de acordo com Maria e Baeninger (2016), este é influenciado pela industrialização e os rumos adotados pelo desenvolvimento econômico do mesmo. Por conseguinte, a migração representa tanto uma forma de sobrevivência quanto uma estratégia que não tem a garantia de produzir o efeito positivo que se espera ao migrar, podendo ainda produzir um efeito positivo ou negativo na região de origem, caso os que migrarem forem mais ou menos pobres. Aliás, o maior nível de pobreza impõe entraves à migração, representando menor probabilidade desse indivíduo migrar. Em contrapartida, pode acontecer um atrofiamento das regiões de destino "a nível intra-urbano, à medida que os pobres são espacialmente segregados e confinados às periferias (com pouco acesso a serviços, além de serem áreas de vulnerabilidade social e ambiental)" (MARIA; BAENINGER, 2016, p.360).

Vilela e Monsma (2015) ressaltaram que certos tipos de empregos retêm mais os migrantes, a exemplo disso, os gerados pela construção civil ou o braçal rural. Enquanto que, os nativos ocupam outras categorias de empregos. Além disso, esse tipo de segregação pode dar condições de existir atividades econômicas, ou quando elas já existem, de operar em escalar maior, pois, se não fosse o migrante, essas atividades mudaram para países que oferecem menores salários. Assim, o migrante em São Paulo é empregado essencialmente na indústria da construção civil, na agricultura e usinas, ao passo que a viabilização dessas atividades gera ainda melhores oportunidades para os nativos, especialmente para nativos brancos. Para as mulheres, a correlação entre o aumento salarial devido à presença de migrantes é menor do que para os homens, pois, as migrantes e negras nativas competem pelo mesmo tipo de trabalho.

Visto que alguns estudos apontam para a migração como uma alternativa diante das poucas oportunidades a disposição dos trabalhadores no seu local de origem e, o fator de ser migrante pode condicionar a um tipo de segregação no mercado de trabalho, apresentar-se-á a metodologia utilizada e após as discussões. Objetivou-se contribuir com o entendimento da dinâmica da discriminação em relação ao migrante e nativo no Estado de São Paulo. A fim de que, fosse possível inferir considerações sobre qual a realidade enfrentada, em termos de discriminação salarial, pelos trabalhadores que se deslocam para o Estado de São Paulo em busca de oportunidades de trabalho

\section{METODOLOGIA}

A fim de estudar a dispersão de salários dos indivíduos, foi utilizado o método de decomposição salarial Oaxaca (1973) e Blinder (1973). Para tanto foi utilizada a base de microdados da Pesquisa Nacional de Amostra por Domicílios (PNAD) do ano de 2015, disponibilizada pelo Instituto Brasileiro de Geografia e Estatística (IBGE). A escolha o ano de 2015 deu-se pela última atualização do IBGE da PNAD em website. Foram extraídas as seguintes variáveis para a análise: gênero, cor, idade, experiência, anos de estudo, salário mensal, censo demográfico, naturalidade e atividade econômica. 
Considerou-se para fins metodológicos como não-branco aqueles trabalhadores autodeclarados pardos e negros. Foram retirados da pesquisa trabalhadores que não possuem remuneração, ou seja, a população ocupada é constituída por empregados, empregadores e autônomos a partir dos 14 anos de idade $^{1}$. As atividades econômicas foram subdivididas em grupos setoriais: agricultura, comércio e indústria.

Conforme Mincer (1974), a formação do capital humano tem-se como consideração a educação um dos investimentos de capital, fator relevante para o ciclo de vida do auto-investimento. É verificado o rendimento do indivíduo em relação ao capital humano, em que, a equação de rendimentos tem como calcular o retorno do estudo salientando a extrema relação com o nível de educação na renda do indivíduo e o tempo de experiência no mercado de trabalho.

As equações base para a análise da decomposição salarial de Oaxaca e Blinder são:

$$
\begin{gathered}
Y_{i}^{H}=\beta_{0}^{H}+\sum_{i=1}^{n} \beta_{j}^{H} X_{j i}^{H}+u_{i}^{H} \\
Y_{i}^{L}=\beta_{0}^{L}+\sum_{i=1}^{n} \beta_{j}^{L} X_{j i}^{L}+u_{i}^{L}
\end{gathered}
$$

O logaritmo natural do salário é interpretado por $Y_{i}^{H}$ e $Y_{i}^{L}, X_{j i}^{H}$ e $X_{j i}^{L}$ e como as particularidades que os trabalhadores apresentam na variável independente. Na equação (1) e (2) tem como apresentação o e como representação homem e mulher, em que o homem é um conjunto promissor e a mulher como não promissor. De maneira que, é utilizado o método Mínimos Quadrados Ordinários (MQO):

$\left(\bar{Y}^{H}-\bar{Y}^{L}\right)=\left(\beta_{0}^{H}-\beta_{0}^{L}\right)+\sum j \overline{X_{j}^{L}}\left(\beta_{j}^{H}-\beta_{j}^{L}\right)+\sum j \beta_{j}^{H}\left(\overline{X_{j}^{H}}-\overline{X_{j}^{L}}\right)$

Em que $\left(\beta_{0}^{H}-\beta_{0}^{L}\right)$ representa a parcela não explicada do diferencial, $\sum j \overline{X_{j}^{L}}\left(\beta_{j}^{H}-\beta_{j}^{L}\right)$ descreve a fração do diferencial das remunerações atribuídas a diferença dos coeficientes, fator que indica existência ou não de diferenças dos grupos estudados com desenvolvimentos idênticos individuais. $\sum j \beta_{j}^{H}\left(\overline{X_{j}^{H}}-\overline{X_{j}^{L}}\right)$ Já explica a representação a parcela do diferencial atribuído às diferenças de capacitações (BLINDER, 1973; OAXACA, 1973).

Desse modo, a parcela não explicada do diferencial e a fração do diferencial das remunerações atribuídas a diferença dos coeficientes são dadas como:

$$
\left(\beta_{0}^{H}-\beta_{0}^{L}\right)+\sum j \overline{X_{j}^{L}}\left(\beta_{j}^{H}-\beta_{j}^{L}\right)
$$

É apresentada a separação à discriminação no mercado de trabalho e atributos particulares ou de incorporação no mercado de trabalho, isto é, discriminações externas. Entende-se como discriminação no mercado de trabalho como salários distintos a indivíduos com a mesma capacidade e características em ocupações exatamente iguais.

\section{RESULTADOS E DISCUSSÕES}

Como escopo do proposto estudo é analisar a discriminação salarial entre nativos e não nativos por atividade econômica, a Figura 1 apresenta um panorama geral da situação da migração no Brasil para o ano de 2010, data do último censo demográfico. O Estado de São Paulo conta com o maior número de pessoas não naturais da Unidade da Federação, por tempo ininterrupto de residência, o que representou 8.538.510 de pessoas nessa condição, o que representa $32,15 \%$ do Brasil (CENSO, 2010).

Internamente, por meio da visualização da dinâmica dos municípios paulistas representada pela Figura 2 é possível inferir que existe uma concentração de migrantes em torno da capital do Estado, São Paulo (de acordo com o Censo em 2010, eram 2.599.010 indivíduos, $9,80 \%$ da população migrante do país), caracterizada por ser uma região metropolitana com importância econômica significativa em termos de Brasil. Isso vai ao encontro com Schultz (1973) e Santin (2008), os quais enfatizam porque as pessoas migram em busca de melhores oportunidades de emprego.

\footnotetext{
${ }^{1}$ Delegado no artigo 403 da Consolidação das Leis do Trabalho (BRASIL,
} 2000). 
Figura 1 - Pessoas não naturais da Unidade da Federação, por tempo ininterrupto de residência na Unidade da Federação (2010) - Pessoas

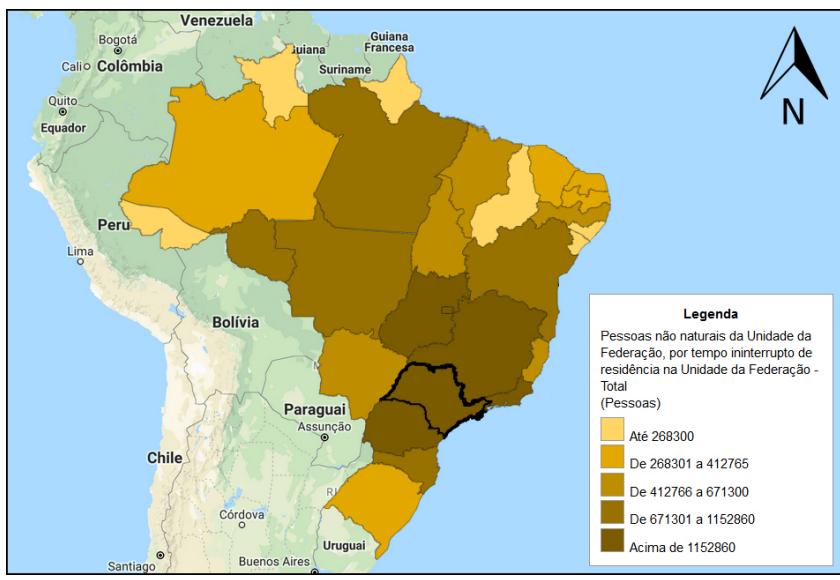

Fonte: Censo, 2010.

As pessoas migram para lugares que, de acordo com Herédia (2010) possuam melhores oportunidade do que as que estariam disponíveis no lugar onde essas pessoas já residiam. O que torna uma localidade atrativa é o fato de ser um espaço de trabalho, possuir economia diversificada.

Figura 2 - Pessoas não naturais da Unidade da Federação, por tempo ininterrupto de residência na Unidade da Federação - 2010 - Total - Pessoas - São Paulo

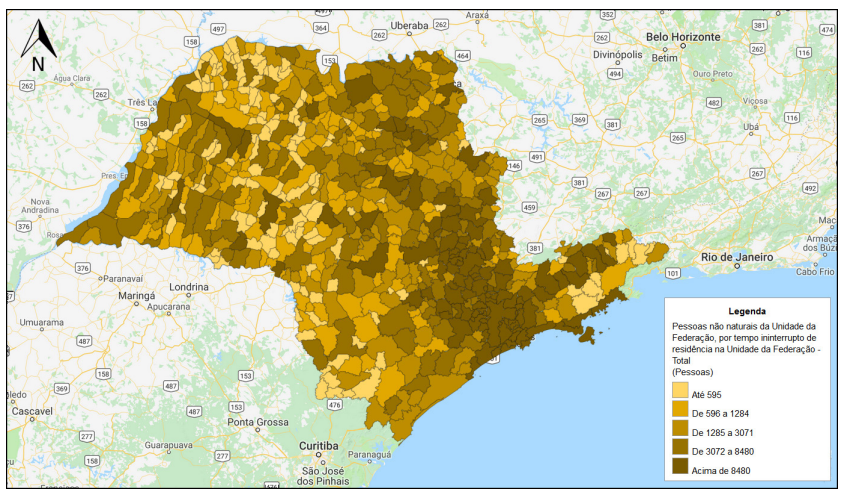

Fonte: Censo, 2010.

Visto que o Estado de São Paulo possui uma grande quantidade de pessoas não-nativas vivendo em seu território a Tabela 1 apresenta a média da idade, experiência, anos de estudo, salário mensal, horas de trabalho e salário hora para homens e mulheres nativo e não nativo.
Tabela 1 - Comparação do perfil da população nativa e não nativa de acordo com o sexo

\begin{tabular}{l|c|c|c|c}
\hline & \multicolumn{2}{|c|}{ Nativo } & \multicolumn{2}{c}{ Não nativo } \\
\hline & Homem & Mulher & Homem & Mulher \\
\hline Idade (média) & 41,06 & 40,35 & 42,04 & 41,48 \\
\hline $\begin{array}{l}\text { Experiência } \\
\text { (média) }\end{array}$ & 24,33 & 23,55 & 26,94 & 25,66 \\
\hline $\begin{array}{l}\text { Anos de } \\
\text { estudo (média) }\end{array}$ & 10,73 & 10,80 & 9,11 & 9,83 \\
\hline $\begin{array}{l}\text { Salário Mensal } \\
\text { (média) }\end{array}$ & $\mathrm{R} \$$ & $\mathrm{R} \$$ & $\mathrm{R} \$$ & $\mathrm{R} \$$ \\
\hline $\begin{array}{l}\text { Horas de } \\
\text { trabalho } \\
\text { (semanal/ }\end{array}$ & $43,643,23$ & $1.490,06$ & $2.065,42$ & $1.344,58$ \\
$\begin{array}{l}\text { Média) } \\
\text { Salário Hora } \\
\text { (média) }\end{array}$ & $\mathrm{R} \$ 14,13$ & $\mathrm{R} \$ 7,73$ & $\mathrm{R} \$ 11,57$ & $\mathrm{R} \$ 10,98$ \\
\hline
\end{tabular}

Fonte: Elaborado pelos autores (2019).

É possível observar em relação à idade que em média são mais velhos os homens não nativos, seguidos das mulheres não nativas, do homem nativo e por fim da mulher nativa. Em termos de experiência, a realidade encontrada por meio da média é igual ao da idade média. Ou seja, os mais experientes em média são em ordem decrescente os homens não nativos, as mulheres não nativas, o homem nativo e por fim da mulher nativa. Essa informação é coerente, pois, intenta-se que, como a experiência é medida em anos, as pessoas mais velhas apresentaram maior experiência.

Em relação à média de anos de estudo o resultado chama a atenção porque as mulheres possuem maior tempo de estudo do que os homens em ambos os casos: nativo e não nativo. Sendo que a mulher nativa é a que apresenta maior escolaridade, enquanto o homem não nativo apresenta a menor escolaridade. Ao analisar o salário médio mensal a realidade é um tanto diversa da encontrada no item educação. O maior salário é o do homem nativo, seguido do homem não nativo (aquele que apresentou a menor média de anos de estudo), seguidos da mulher nativa e depois da mulher não nativa.

Assim, visualiza-se um cenário geral em que a mulher investe mais em educação do que os homens, mas o salário ainda é menor para ambos os cenários em que estão presentes os homens: nativos ou não nativos. O mais curioso é que apesar da escolaridade média da mulher não nativa ser superior ao do homem 
não nativo e possuir experiência maior do que homens e mulher nativos, o salário médio é o menor.

Outro fato chama a atenção, a carga horária média enfrentada por essas pessoas e o salário/hora médio recebido. É importante essa análise porque pode-se verificar se a origem da discrepância da média de salário recebida está na quantidade de horas trabalhadas.

Assim, o homem não nativo tem a maior carga de trabalho semanal média, seguido do homem e da mulher nativa. A menor carga horária semanal média é o das mulheres não nativas que recebem também a menor remuneração média mensal. Apesar do homem não nativo ter uma carga horária média maior, são os homens nativos que auferem maior rendimento médio mensal.

Quando a análise é feita para o salário hora médio, o que se percebe é que as mulheres nativas estão em pior situação do que aos demais. Os homens recebem mais por hora trabalhada em média do que as mulheres, principalmente quando se trata do homem nativo.

Dessa forma, a partir da análise dos dados apresentados, verifica-se que a média de anos de estudo e experiência não foram suficientes para representar a diferença média de rendimento entre as categorias estudas: homem nativo e não nativo e mulher nativa e não nativa. Com destaque para a tendência positiva em termos de rendimentos e carga horária de trabalho para o homem nativo. As mulheres apesar de apresentarem maior escolaridade auferem rendimento menor médio mensal e por hora.

É importante frisar que a remuneração varia por fatores relacionados a característica demográfica, mas também devido ao ramo de atividade em que o indivíduo está inserido. Assim, a Tabela 2 apresenta o resultado para aplicação da metodologia OaxacaBlinder para determinação da discriminação. Isso está de acordo com Arbache (2000) e Lima (1980), que enfatizam que a escolaridade pode não ser suficiente para explicar o rendimento auferido, já que algumas atividades remuneram melhor ou pior do que outras.
Tabela 2 - Decomposição de Oaxaca-Blinder entre nativos e não-nativos no setor agrícola para no estado de São Paulo, 2015

\begin{tabular}{c|c|c|l}
\hline & Coeficiente & Desvio padrão & \\
\hline Nativo & 1,738572 & 0,0714813 & $*$ \\
\hline Não nativo & 1,640998 & 0,0553387 & $*$ \\
\hline Diferença & 0,0975739 & 0,0903988 & $*$ \\
\hline Explicada & 0,1565457 & 0,0537597 & $*$ \\
\hline Não explicada & $-0,0589717^{2}$ & 0,0839924 & $* *$ \\
\hline
\end{tabular}

* Estatisticamente significante a $5 \%$

** Estatisticamente significante a $10 \%$

Fonte: Elaborado pelos autores, 2019.

A Tabela 2 mostra a diferença de remuneração entre o migrante e o não migrante do Estado de São Paulo que está empregado no grupo agrícola. Percebese que existe uma diferença entre a remuneração do nativo e não nativo na amplitude de $(0,10)$. Sendo que dessa diferença, $(0,15)$ é explica por fatores que naturalmente é esperado que resulte em diferencial de salário, como por exemplo: idade, escolaridade, experiência. Já $(-0,056)$ não é explicado. Ou seja, dentro de um grupo homogêneo de pessoas que trabalham no ramo agrícola, elas enfrentam discriminação pelo fator de ser migrante (não nativo).

Isso vai de encontro com o que foi abordado por Dedecca e Cunha (2004), a respeito dos imigrantes quando o assunto é trabalho. Isso porque, os imigrantes estão mais propensos ao subemprego, desemprego e sobre qualificação.

Tabela 3 - Decomposição de Oaxaca-Blinder entre nativos e não-nativos no setor da indústria para no estado de São Paulo, 2015

\begin{tabular}{l|c|c|l}
\hline & Coeficiente & Desvio padrão & \\
\hline Nativo & 2,232253 & 0,0297239 & $*$ \\
\hline Não nativo & 2,034024 & 0,0260392 & $*$ \\
\hline Diferença & 0,1982282 & 0,0395164 & $*$ \\
\hline Explicada & 0,0779644 & 0,0214039 & $*$ \\
\hline Não explicada & 0,1202639 & 0,0356047 & $*$
\end{tabular}

* Estatisticamente significante a 5\%

Fonte: Elaborado pelos autores, 2019.

A Tabela 3 insere a discussão o grupo de migrantes e não migrantes que estão empregados no

\footnotetext{
${ }^{2} \mathrm{O}$ sinal negativo leva ao indício de perda de salário por parte de trabalhadores que referiu nativo caso tivessem as mesmas características dos trabalhadores que não nativos (RUSSO; DIAS, 2015).
} 
ramo industrial. A diferença salarial observada entre os dois grupos de trabalhadores é de $(0,20)$, ou seja, o diferencial de remuneração é maior quando se considera o emprego na indústria. Principalmente pelo fato que $(0,12)$ dessa diferença trata-se de discriminação. Ou seja, o migrante e o não migrante podem possuir a mesma escolaridade, experiência e idade que mesmo assim renda auferida pelo mesmo é menor.

Assim como Arbache (2000), o que se inferi a partir desse resultado é que a discriminação é oriunda de uma preferência do empregador em pagar salários maiores a determinado trabalhador, mesmo quando possuem as mesmas habilidades e funções. Essa preferência é respaldada por determinadas características demográficas em relação a outras.

Tabela 4 - Decomposição de Oaxaca-Blinder entre nativos e não-nativos no setor comércio para no estado de São Paulo, 2015

\begin{tabular}{c|c|c|c}
\hline & Coeficiente & Desvio padrão & \\
\hline Nativo & 1,974975 & 0,0244819 & $*$ \\
\hline Não nativo & 1,907487 & 0,0226179 & $*$ \\
\hline Diferença & 0,0674879 & 0,0333307 & $*$ \\
\hline Explicada & 0,0558481 & 0,0160265 & $*$ \\
\hline Não explicada & 0,0116397 & 0,0304754 & $* *$ \\
\hline
\end{tabular}

* Estatisticamente significante a 5\%

** Estatisticamente significante a $10 \%$

Fonte: Elaborado pelos autores, 2019.

A Tabela 4 apresenta o resultado da decomposição Oaxaca-Blinder para o nativo e não nativo empregado no comércio. Trata-se do segmento de atividade econômica que apresenta a menor diferença entre a renda auferida por trabalhadores nativos ou não nativos. Assim, verifica-se que esse diferencial é de $(0,07)$ e que $(0,012)$ é não explicado, tratando-se, portando, de discriminação.

Dessa forma, quando a análise leva em consideração o diferencial de salário oriundo da discriminação entre migrante e não migrante do Estado de São Paulo pela decomposição Oaxaca-Blinder, fica evidente que existe discriminação entre esses dois grupos de trabalhadores e que a discriminação apresenta intensidade diferente dependendo do ramo de atividade que o mesmo está inserido. Assim, percebe-se que a maior discriminação está na indústria.

Assim como destacado por Barros, Franco e Mendonça (2007) o que representa a discriminação é situações em que os trabalhadores são perfeitamente substituíveis, por apresentarem a mesma produtividade. Porém, existem diferenças oriundas de algumas de suas características.

\section{CONSIDERAÇÕES FINAIS}

Ao analisar a diferença salarial entre nativos e não nativos do estado de São Paulo que estavam empregados na agricultura, comércio e na indústria verificou-se em maior parte, que o nativo prevalece à privilégios ou em condições similares ao dos não nativos no mercado de trabalho. Desse modo, a diferença salarial entre os trabalhadores nativos e não nativos é maior na indústria, seguido da agricultura e por último, o setor de comércio. Os resultados indicaram que o nativo em São Paulo está em uma melhor posição hierárquica ocupacional no mercado de trabalho, quanto se trata de remuneração, do que os não nativos.

Destaca-se que a discriminação salarial acontece entre dois ou mais indivíduos que possuem a mesma qualificação para determinado posto de traba1ho. Não caracterizando como discriminação quando a diferença salarial é oriunda da diferença de qualificação da mão-de-obra. Fato que torna ainda mais preocupante a situação do migrante frente ao nativo no mercado de trabalho, variável que deve ser considerada pelo migrante.

A conjuntura a ser destacada é o status do indivíduo migrante que tem impacto negativo no mercado de trabalho do estado de São Paulo, evidenciado no coeficiente de diferença salarial não explicada oriundo da decomposição Oaxaca-Blinder. Dessa forma, o estudo evidenciou a realidade discriminatória no mercado de trabalho paulista, através dos resultados econométricos para os trabalhadores nativos e não nativos do estado de São Paulo, empregados na agricultura, comércio ou indústria.

Assim, presume-se que para alcançar mudanças na estrutura social brasileira, são necessárias modificações, entre elas a não discriminação do migrante ao procurar cidades com melhores condições de vida, acesso à educação de qualidade, mobilidade urbana e saúde. 


\section{RERERÊNCIAS}

ANDRADE, Thompson Almeida; SANTOS, Ângela M.S.P.; SERRA, Rodrigo Valente. Fluxos migratórios nas cidades médias e regiões metropolitanas brasileiras: a experiência do período de 1980-1996. In: ANDRADE, Thompson Almeida e SERRA, Rodrigo Valente (Org.). Cidades médias brasileiras. Rio de Janeiro: IPEA, 2001.

ARBACHE, Jorge Saba. Determinação e Diferencial de Salários no Brasil. In: FONTES, Rosa; ARBEX, Marcelo A. (Ed.). Desemprego e mercado de trabalho: ensaios teóricos e empíricos. Viçosa: UFV, 2000. p. 125-184.

BAENINGER, Rosana. São Paulo e suas migrações no final do século 20. São Paulo Perspec., São Paulo, v. 19, n. 3, p. 84-96, Set. 2005.

BAENINGER, Rosana. Migração, Migrações. Idéias, [S.1.], v. 2, n. 1, p. 31-41, ago. 2011.

BARROS, Ricardo Paes de; FRANCO, Samuel; MENDONÇA, Rosane. Discriminação e segmentação no mercado de trabalho e desigualdade de renda no brasil. Brasília: IPEA, 2007. (texto para discussão n 1288).

BLINDER, Alan. S. Wage discrimination: reduced form and structural estimates. The Journal of Human Resources. v. 8, n. 4, 1973.

BRASIL. Artigo 403, de 2000. Consolidação Das Leis Do Trabalho, Brasília, DF, março 2000. Disponível em http:// www.planalto.gov.br/ccivil_03/decreto-lei/Del5452.htm Acesso em 03/03/2019.

CENSO. Pessoas não naturais da Unidade da Federação, por tempo ininterrupto de residência na Unidade da Federação - Total: IBGE. 2010. Disponível em: $\quad<$ https://censo2010.ibge.gov.br/amostra/index. html?local=0\&var=7946>. Acesso em: 19 fev. 2019.

DEDECCA, Cláudio Salvadori; CUNHA, José Marcos Pinto. Migração e trabalho: uma abordagem não algoz. In: Encontro Nacional de Estudos Populacionais, 12, 2000, Caxambu. Anais... Belo Horizonte: ABEP, 2000.

DEDECCA, Cláudio Salvadori; CUNHA, José Marcos Pinto. Migração, trabalho e renda nos anos 90: o caso da Região Metropolitana de São Paulo. Revista Brasileira de População, Campinas, v. 21, n.1, p. 49-66, 2004.

GAMA, Luiz Carlos Day; MACHADO, Ana Flávia. Migração e rendimentos no Brasil: análise dos fatores associados no período intercensitário 2000-2010. Estudos Avançados: Trabalho, Emprego e Renda, São Paulo, v. 28, n. 81, p.155-174, ago. 2014.

HERÉDIA, Vania. Migrações internas e mercado de trabalho. In: Fazendo Gênero, 9, 2010, Florianópolis. Anais Fazendo Gênero 9 - Diásporas, Diversidades, Deslocamentos. Florianópolis: Universidade Federal de Santa Catarina, 2010. p. 1 - 6.
INSTITUTO BRASILEIRO DE GEOGRAFIA E ESTATÍSTICA. Pesquisa Nacional por Amostra de Domicílios, 2015. Rio de Janeiro: IBGE. Disponível em: $<$ http://www. ibge.gov.br>. Acesso em: 5 de janeiro de 2019.

LIMA, Ricardo. Mercado de Trabalho: O capital humano e a teoria da segmentação. Pesq. Plan. Econ, Rio de Janeiro, v. 10, n. 1, p.217-272, abr. 1980.

LOWELL, Peggy. A. Race, Gender and Development in Brazil. Latin American Research Review, v. 20, n. 3, 1995.

MARIA, PierFrancesco de; BAENINGER, Rosana. Migração e pobreza: primeiras aproximações para o Brasil (19952014). In: SEMINÁRIO DE PESQUISA EM CIÊNCIAS HUMANAS, 2016, Londrina. XI SEMINÁRIO DE PESQUISA EM CIÊNCIAS HUMANAS - Humanidades, Estado e desafios didático-científicos. Londrina: SEPECH, 2016. p. 359 - 372.

MINCER, Jacob. Schooling, experience and earnings. New York: National Bureau of Economic Research, 1974.

OAXACA, Ronald L. Male-female wage differentials in urban labor markets. International Economic Review, v.14, Issue 3, 1973.

PIORE, Michael J. Birds of passage: Migrant labor and industrial societies. Cambridge, University Press Cambridge. 1979.

RUSSO, Letícia Xander; DIAS, Joilson. O Estado de Saúde Individual e as Diferenças Salariais no Brasil em 2003 e 2008. Revista de Economia, v. 41, n. 2 (ano 39), p. 79-98, mai./ago. 2015.

SANTIN, Valter Foleto. Migração e discriminação de trabalhador. Argumenta Journal Law, Jacarezinho, v. 1, n. 7, p.131-140, 2008.

SCHULTZ, Theodore W. O capital Humano: Investimento em Educação e Pesquisa. Rio de Janeiro: Zahar Editores, 1973.

VILELA, Elaine Meire; MONSMA, Karl. Migração interestadual e desigualdade racial: evidência do Estado de São Paulo. Sociologias, Porto Alegre, v. 17, n. 40, p.256291, dez. 2015. 